Article

\title{
Synthesis of Lipoamino Acids and Their Activity against Cerebral Ischemic Injury
}

\author{
Li-Yun Yao, Qi Lin, Yin-Yao Niu, Ke-Min Deng, Jian-Hua Zhang and Yang Lu * \\ Institute of Pharmaceutical Research, Shanghai Jiao Tong University School of Medicine, Shanghai \\ 200025, China
}

* Author to whom correspondence should be addressed; E-Mail: huaxue@shsmu.edu.cn.

Received: 14 August 2009; in revised form: 22 September 2009 / Accepted: 29 September 2009 / Published: 12 October 2009

\begin{abstract}
A series of lipoamino acids were synthesized and their neuroprotective effect against brain ischemia induced by oxygen-glucose deprivation (OGD) on rat cerebral slices was evaluated. Among these compounds, $N$-stearoyl-L-tyrosine (4), $N$-stearoyl-L-serine (5) and $N$-stearoyl-L-threonine (6) exhibited good neuroprotective activity. We found that the neuroprotective activity of lipoamino acids depended on the acyl group, the presence of a free carboxylic function and a free hydroxyl group at the branched chain of the amino acids. The results also showed that 5 was the most active compound, protecting rat brain slices against OGD as well as hydrogen peroxide $\left(\mathrm{H}_{2} \mathrm{O}_{2}\right)$ insult at the range of 1-10 M.
\end{abstract}

Keywords: lipoamino acids; neuroprotection; brain ischemia; oxygen-glucose deprivation

\section{Introduction}

Cerebral ischemia would lead to brain damage in pathogenetic mechanisms including excitotoxicity, over production of free radicals, inflammation and apoptosis [1-3]. One of the challenging brain damage therapies is to inhibit the toxic pathways by activating endogenous neuroprotective system to stimulate cellular responses against the damage induced by severe ischemic events [4-6]. A variety of chemical agents, such as glumatate receptor antagonists, antioxidants, antiinflammatory and anti-apoptotic agents, have been used to initiate neuroprotection by mediating the processes [7-9]. Despite aggressive investigations aimed at development of innovative neuroprotective drugs, few are in fact clinically effective [10]. 
Recent evidences suggest that $\mathrm{N}$-arachidonoylethanolamine (anandamide, AEA, Figure 1), an endocannabinoid, plays a crucial neuroprotective role in certain neurodegenerative diseases [11-13]. Therefore, the design, synthesis and study of analogs of AEA with the aim of obtaining compounds with neuroprotective activity are ongoing research in our group.

Figure 1. The structures of AEA and its endogenous analog (NAGly).

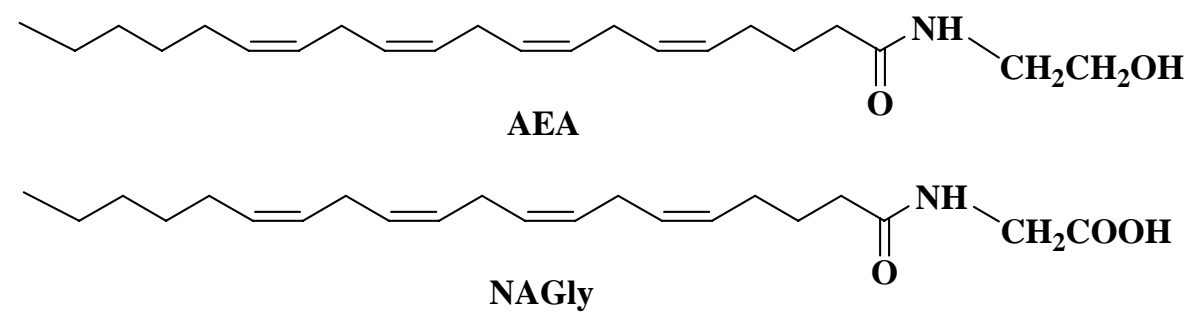

As chemical entities, lipoamino acids (LAs, Figure 2), the fatty acid-amino acid conjugates, exist as endogenous substances with multiple biological activities [14]. They appear to have close relationships with AEA, not only structurally, but also in terms of biological activities such as analgesia, antiinflammatory effects, inhibition of cell proliferation, calcium ion mobilization and neural protection [15]. For example, $N$-arachidonoylglycine (NAGly, Figure 1) is an endogenous constituent in many tissues and might have analgesic properties similar to those reported for AEA [16]. Recently, we found that stearic acid protected rat brain slices or neurons in vitro against apoptosis induced by OGD, NMDA or $\mathrm{H}_{2} \mathrm{O}_{2}$ [17]. In terms of the structure and activity of both LAs and stearic acid, we deduced that LAs as amino acid conjugates with stearic acid might show neuroprotective activity. It is interesting to synthesize a series of $N$-stearoylamino acids and its analogues and evaluate their potential neuroprotective activity. By changing the structure and stereochemistry of the aminodonors, we would be able to find novel neuroprotective agents and fine-tune their SAR toward obtaining potent protectants. The present paper reports the synthesis of this library of LAs (Figure 2) and evaluation of their activity against cerebral ischemic injury in vitro.

Figure 2. The general structure of LAs.<smiles>[R]C(NC(=O)CCC)C(=O)O</smiles>

\section{Results and Discussion}

\subsection{Chemical synthesis}

A series of $\mathrm{N}$-stearoylamino acids and their derivatives (Table 1) were synthesized using the procedures below, shown in Scheme 1 [18]. Briefly, commercially available stearic acid was reacted with $N$-hydroxysuccinimide to provide octadecanoic acid 2,5-dioxo-pyrrolidin-1-yl ester, which was combined with appropriate amino acids (or amino acid methyl esters) to give $N$-stearoylamino acids 111 and $N$-stearoylamino acid methyl esters 12-14. The acylation of amine of amino acids with higher yield is especially suitable for the synthesis of LAs for its effective chemoselectivity towards the 
amino rather than hydroxyl group in the side-chains of amino acids. Compounds $\mathbf{1 5}$ and $\mathbf{1 6}$ were synthesized following the synthetic route of $\mathbf{4}$ from palmitic and lauric acids instead of stearic acid, respectively. Compound 17 was obtained by reducing 4 with $\mathrm{NaBH}_{4}-\mathrm{I}_{2}$ by the method reported by Mckennon et al. [19]. The $\mathrm{NaBH}_{4}-\mathrm{I}_{2}$ reagent system, by generating the reactive (acyloxy)borohydride $\left(\mathrm{RCOOBH}_{2}\right)$, is more selective towards the carboxylic group rather than the amide group, because of the presence of the free carboxylic group in LAs [20]. The structures of all synthesized compounds were confirmed by ${ }^{1} \mathrm{H}$ - and ${ }^{13} \mathrm{C}-\mathrm{NMR}$, and the spectroscopic properties and analytical data were in accord with the proposed structures.

Scheme 1. The synthetic rout to $N$-stearoylamino acids and their methyl esters.

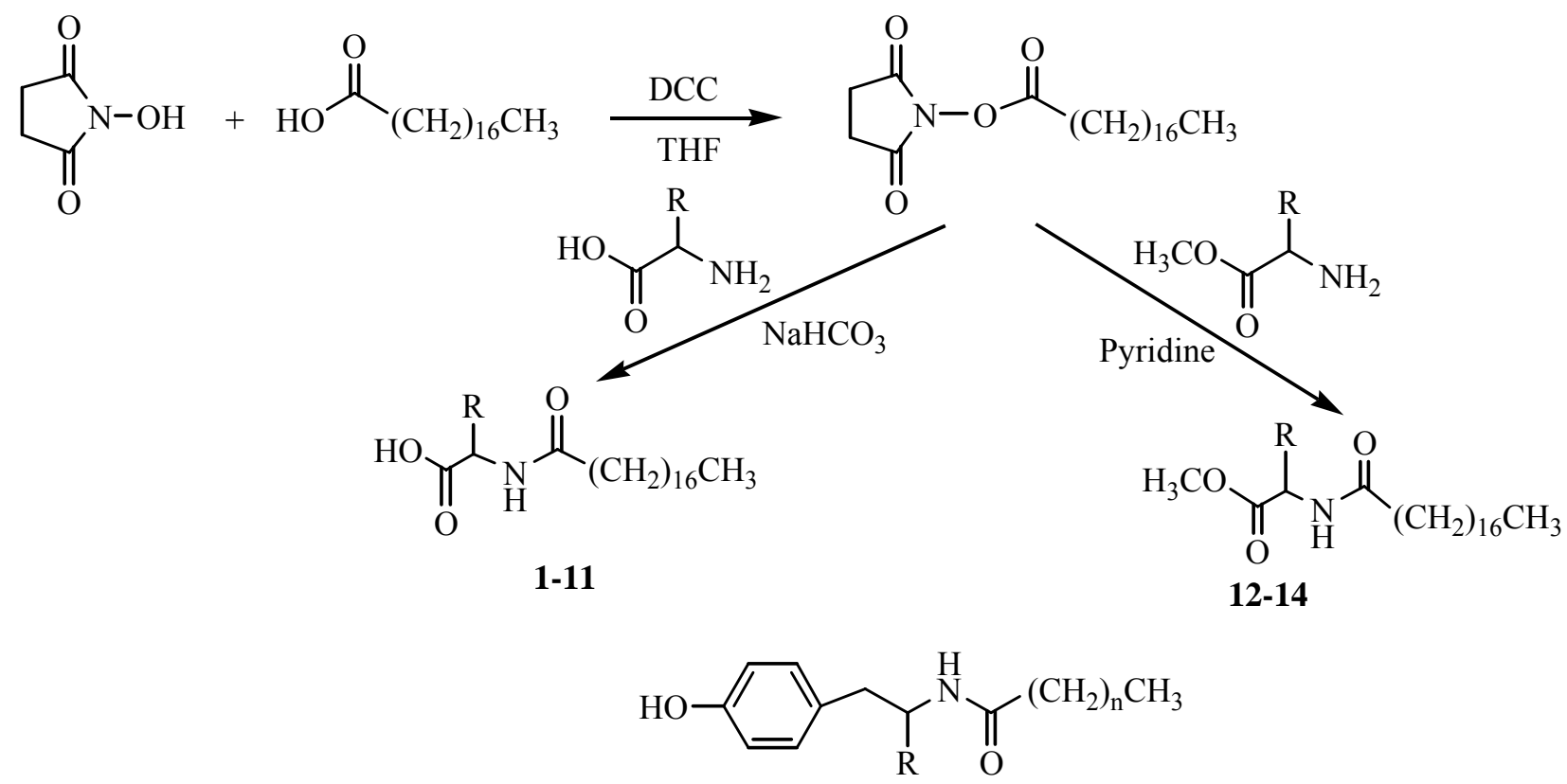

15-17

\subsection{Biological activity}

\subsubsection{Effect of the synthesized compounds on OGD-insulted rat brain slices}

The compounds shown in Table 1 were screened for neuroprotective activity against brain ischemia induced by OGD insult on rat cerebral slices [21]. The screening concentrations of compounds were determined by our preliminary dose-response study (data not shown). The tissue activity of the brain slices was expressed as percentage of that of the control before brain injury. In Figure 3, the tissue activities of brain slices pretreated with 1-7 $(66.5 \%-82.2 \%)$ were obviously higher than that of the brain slices pretreated with no drug $(51.8 \%)(P<0.05)$, indicating these compounds could reduce the OGD-induced neurotoxicity. Among these compounds, 4, 5 and 6, the three LAs with free hydroxyl groups, showed good tissue activity $(77.5 \%, 82.2 \%$ and $76.5 \%$ respectively), which was similar to that of the standard ketamine $(76.7 \%)$ and they attenuated OGD injury effectively $(P<0.01)$. It's worthy to note that the pretreatment of the brain slices with target compounds did not influence the availability of brain ischemia model within the effective concentration (data not shown). Compound 4 showed a significant protective effect on insulted brain slices, but its homologues $\mathbf{1 5}$ and $\mathbf{1 6}$ had little effect 
(53.4\%, 56.6\% respectively), indicating that the length of the alkyl moiety of the LAs plays a critical role in the neuroprotective effect. $N$-stearoylamino acid methyl esters 12-14 and $N$-stearoyl-L-tyrosinol (17) presented little neuroprotective effect, implying that the presence of a free carboxylic group in the stearic amides may be necessary for their activity. It is interesting that an identical neuroprotective effect has been observed for 1 (L-phenylalanine) and 2 (DL-phenylalanine). A detailed SAR study concerning the stereochemistry of LAs and their neuroprotecive activity is currently under way in our laboratory.

Table 1. Library of LAs.

\begin{tabular}{|c|c|}
\hline Chemical Name & $\mathbf{R}$ \\
\hline 1. $N$-stearoyl-L-phenylalanine & $-\mathrm{CH}_{2}-10$ \\
\hline 2. $N$-stearoyl-DL-phenylalanine & $-\mathrm{CH}_{2}--1$ \\
\hline 3. $N$-stearoyl-L-proline & 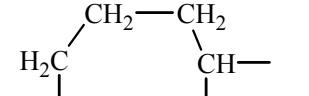 \\
\hline 4. $N$-stearoyl-L-tyrosine & $-\mathrm{CH}_{2}-\backslash-\backslash \mathrm{OH}$ \\
\hline 5. $N$-stearoyl-L-serine & $-\mathrm{CH}_{2} \mathrm{OH}$ \\
\hline 6. $N$-stearoyl-L-threonine & $-\underset{\mathrm{CH}_{3}}{\mathrm{CHOH}}$ \\
\hline 7. $N$-stearoyl-L-tryptophan & $-\mathrm{CH}_{2}$ \\
\hline 8. $N$-stearoyl-L-leucine & $-\mathrm{CH}\left(\mathrm{CH}_{3}\right)_{2}$ \\
\hline 9. $N$-stearoyl-L-cysteine & $-\mathrm{CH}_{2} \mathrm{SH}$ \\
\hline 10. $N$-stearoyl-L-histidine & $-\mathrm{H}_{2} \mathrm{C}-\overbrace{\mathrm{N}=J}^{\mathrm{NH}}$ \\
\hline 11. $N$-stearoyl-L-lysine & $-\left(\mathrm{CH}_{2}\right)_{4} \mathrm{NH}_{2}$ \\
\hline 12. $N$-stearoylglycine methyl ester & $-\mathrm{H}$ \\
\hline 13. $N$-stearoyl-L-glutamic acid dimethyl ester & $-\left(\mathrm{CH}_{2}\right)_{2} \mathrm{COOCH}_{3}$ \\
\hline 14. $N$-stearoyl-L-phenylalanine methyl ester & $-\mathrm{CH}_{2} \leadsto$ \\
\hline 15. $N$--palmitoyl-L-tyrosine & $-\mathrm{COOH}, \mathrm{n}=14$ \\
\hline 16. $N$ - lauroyl-L-tyrosine & $-\mathrm{COOH}, \mathrm{n}=10$ \\
\hline 17. $N$-stearoyl-L-tyrosinol & $-\mathrm{CH}_{2} \mathrm{OH}, \mathrm{n}=16$ \\
\hline
\end{tabular}

Brain slices not only maintain anatomic relations and natural synaptic connectivity in vitro, but also eliminate such in vivo variables as blood flow, temperature, ionic environment, and closely match in vivo conditions [22]. Therefore, increasing numbers of investigation used brain slice models have been reported to study brain function and brain protection. On the other hand, TTC method using 2,3,5triphenyltetrazolium chloride (TTC) as an histopathologic stain for identification of infarcted rat brain tissue is simple, objective and sensitive, and has been widely used in the assessment of brain ischemia in vitro $[23,24]$. In the present study, we evaluated for the first time the effects of LAs on brain slice injury, using the TTC method. 
Figure 3. The tissue activity of rat brain slices pretreated with compounds 1-17 $(10 \mu \mathrm{M})$ in the OGD-induced brain injury model. Brain slices were incubated with different compounds $30 \mathrm{~min}$ prior to and during OGD applications. The viability of brain slices was evaluated by using TTC staining method. Data are means \pm SD from six independent experiments. ${ }^{\#} P<0.01$ vs control group. ${ }^{*} P<0.05,{ }^{* *} P<0.01$ vs OGD group.

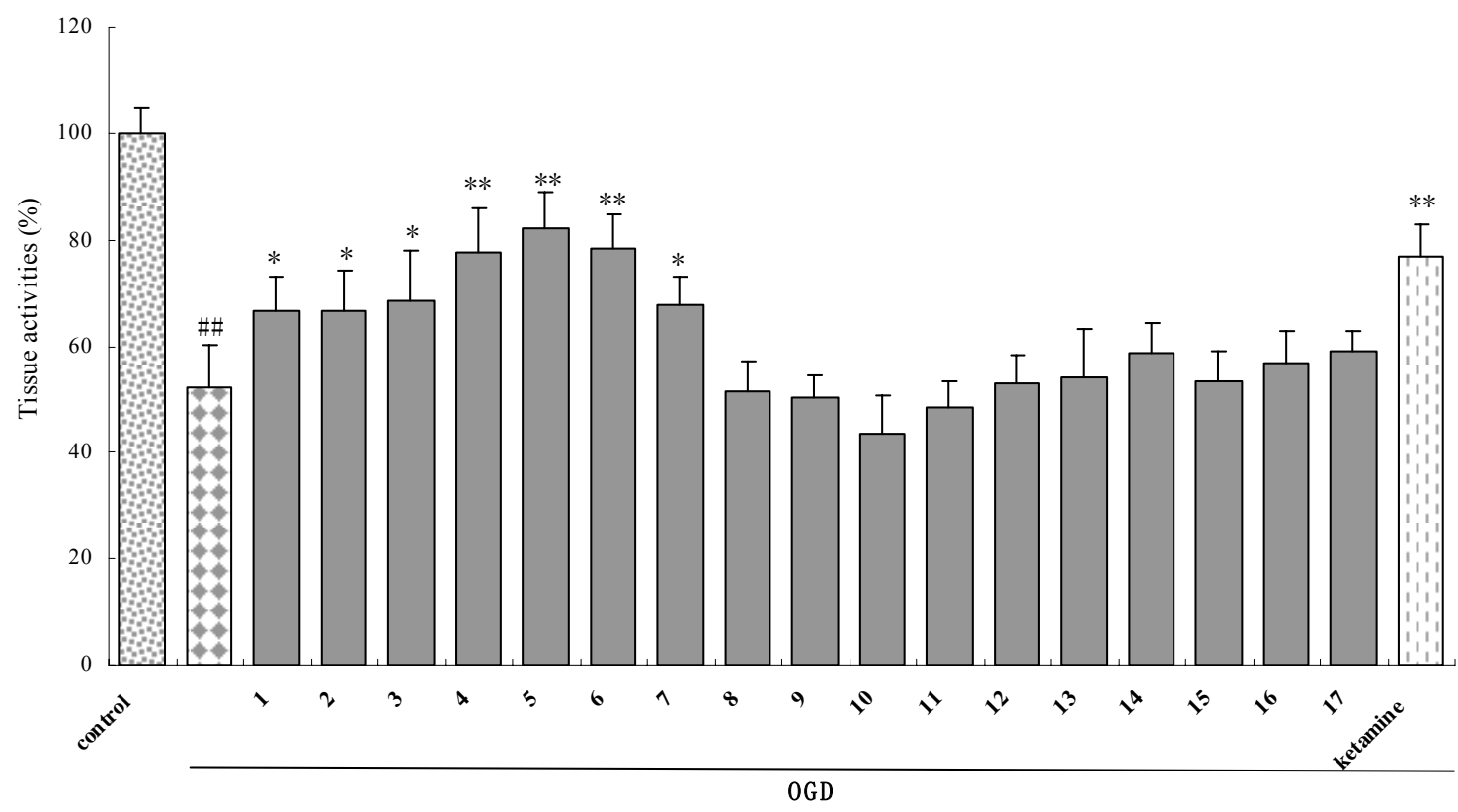

\subsubsection{Effect of 5 on three types of insulted brain slices}

OGD, glutamate $(\mathrm{Glu})$ or $\mathrm{H}_{2} \mathrm{O}_{2}$ damaged models can reflect the pathological characteristics of different phases of ischemia injury (metabolism disorder, toxic amino acid and oxidative stress) [25]. In order to evaluate the possible mechanism of neuroprotective action of these new molecules, we observed the neuroprotective effect of $N$-stearoyl-L-serine (5), the most effective one, against three types of damage brain cortical and hippocampal slices. As shown in Figure 4, compound 5 can concentration-dependently protect brain slices against OGD as well as $\mathrm{H}_{2} \mathrm{O}_{2}$ insult at the range of 1 10 $\mu \mathrm{M}$ (Figures 4A, 4C), and has no protective effect on $1 \mathrm{mM}$ Glu injured brain slices (Figure 4B). The protective effect became less at $20 \mu \mathrm{M}$, implying that 5 at concentration higher than $20 \mu \mathrm{M}$ might show the cytotoxicity.

Since the earlier consequences of applying OGD model in brain ischemia are both increasing release of the excitatory amino acid and excessive activation of oxidative free radicals [26], the observation that 5 might defend against oxidative stress and couldn't inhibit the excitotoxicity of glutamate suggested that neuroprotective effect of $\mathbf{5}$ might be mediated, at least in part, by an antioxidative stress mechanism. These results are in agreement with our recent report showing that neuroprotective effect of $N$-stearoyl-L-tyrosine (4) may be attributed to reduction in lipid peroxidation and DNA fragmentation [27]. The mechanism studies of $\mathbf{4}$ and $\mathbf{5}$ could provide experimental foundation for investigating of their analogues. The detailed mechanism study of these compounds is currently under way in our laboratory. 
Figure 4. The tissue activity of rat brain slices pretreated with $N$-stearoyl-L-serine (5) on rat brain slices induced by OGD, Glu, or $\mathrm{H}_{2} \mathrm{O}_{2}$ insult. Brain slices were incubated with 530 min prior to and during OGD (A), $1 \mathrm{mM}$ glutamate (B), or $2 \mathrm{mM} \mathrm{H}_{2} \mathrm{O}_{2}$ (C) applications. The viability of cortical and hippocampal slices was evaluated by using TTC staining method. $(\mathrm{n}=6)$. Data are mean $\pm \mathrm{SD}$. ${ }^{\# \#} \mathrm{P}<0.01$ vs control group. ${ }^{*} \mathrm{P}<0.05,{ }^{* *} P<0.01$ vs injury group.

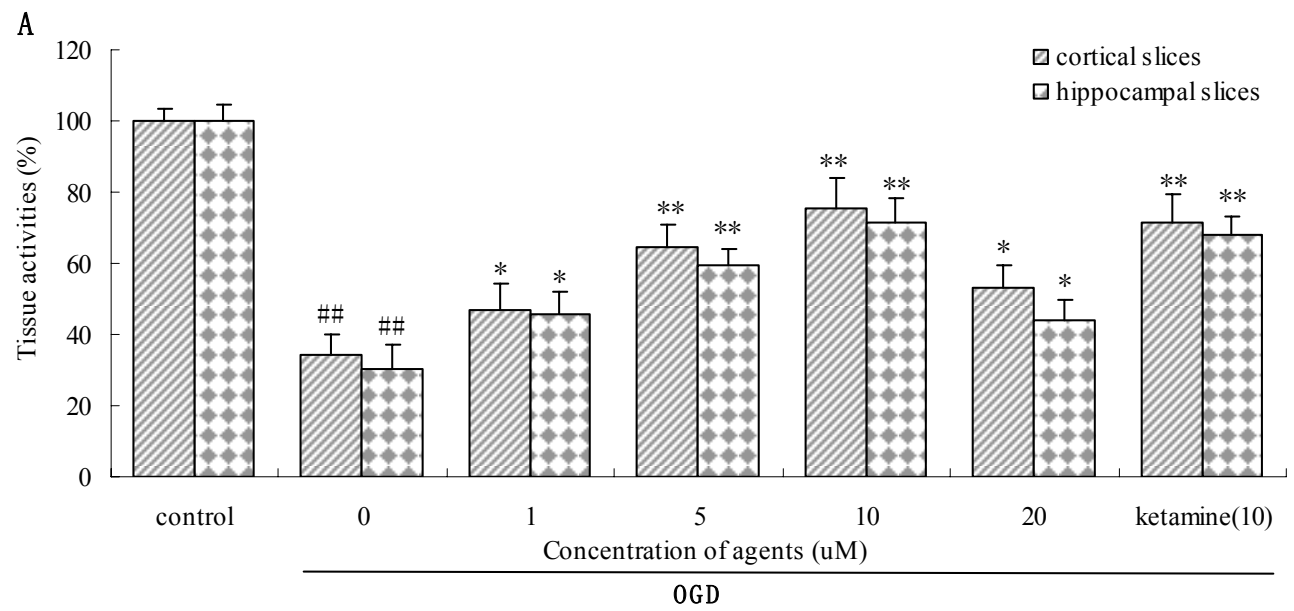

B

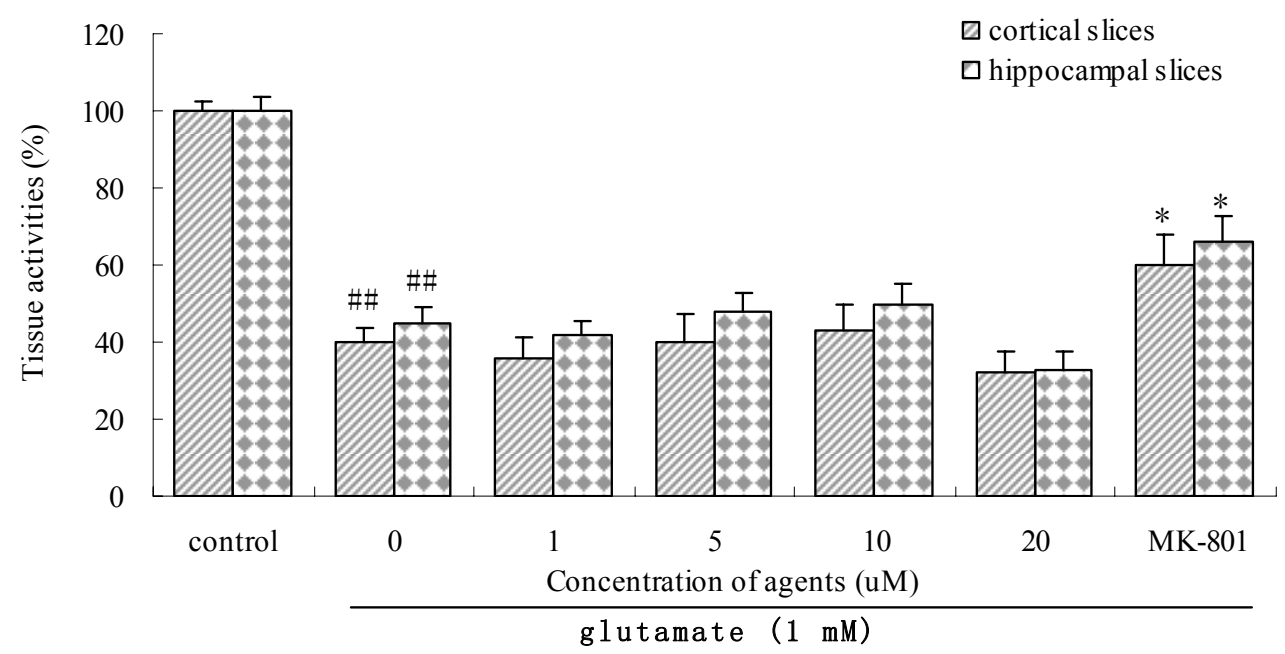

$\mathrm{C}$

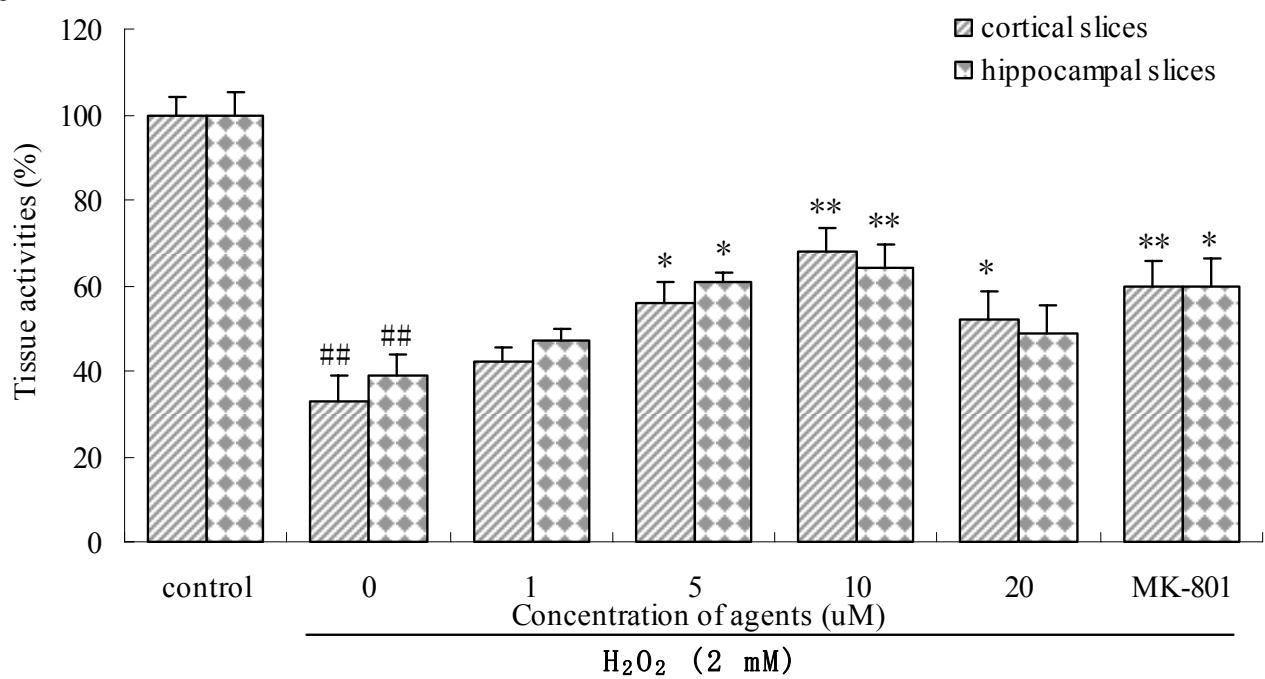




\section{Experimental}

\subsection{General}

Chemicals from Sinopharm Chemical Reagent Co. were used without further purification. Melting points were determined on a WRS-1A melting point apparatus and are uncorrected. Optical rotations were measured at $20 \pm 2^{\circ} \mathrm{C}$ with a Perkin-Elmer $241 \mathrm{MC}$ polarimeter. The progress of reactions was monitored by silica gel $\mathrm{GF}_{254}$ TLC plates. Column chromatography was performed on silica-gel 60 (100-200 mesh ASTM). ${ }^{1} \mathrm{H}$ - and ${ }^{13} \mathrm{C}-\mathrm{NMR}$ spectra were recorded at 400 and $100 \mathrm{MHz}$, respectively, on a Bruker AM-400 spectrometer in chloroform- $d$ solutions (unless stated otherwise), with TMS as internal standard. Chemical shifts were reported in ppm $(\delta)$ downfield from TMS. All the coupling constants $(J)$ are in hertz. Mass spectra were recorded on an Agilent 1100 LC/MSD mass spectrometer. All reported yields correspond to yields of purified products.

\subsection{Preparation of $N$-stearoylamino acids and their derivatives}

\subsubsection{Synthesis and spectroscopic data of $N$-stearoylamino acids 1-11}

Dicyclohexylcarbodiimide (DCC, $9 \mathrm{~g}, 43.6 \mathrm{mmol}$ ) was added to a solution of stearic acid (10 g, $35.2 \mathrm{mmol})$ and $\mathrm{N}$-hydroxysuccinimide $(6 \mathrm{~g}, 52.1 \mathrm{mmol})$ in THF $(80 \mathrm{~mL})$ and the mixture was cooled in an ice-bath under stirring for $16 \mathrm{~h}$ [28]. After filtration, evaporation and recrystallization in isopropanol, octadecanoic acid 2,5-dioxo-pyrrolidin-1-yl ester was obtained with a yield of 90\%, m.p. $76 \sim 78{ }^{\circ} \mathrm{C}$. To a solution of the appropriate amino acid $(5.5 \mathrm{mmol})$ and $\mathrm{NaHCO}_{3}(15 \mathrm{mmol})$ in water $(20 \mathrm{~mL})$ was added dropwise octadecanoic acid 2,5-dioxo-pyrrolidin-1-yl ester (5 mmol) in THF $(20 \mathrm{~mL})$. The mixture was stirring for $6 \mathrm{~h}$ at room temperature. The solvent was removed under reduced pressure. The residue was dissolved in water and adjusted with $\mathrm{HCl}(1 \mathrm{M})$ to $\mathrm{pH} 3$, and the solution was extracted with ethyl acetate $(2$ times $\times 50 \mathrm{~mL})$. The combined organic extracts were successively washed with water and saturated $\mathrm{NaCl}$. Then the organic phase was dried over anhydr. $\mathrm{Na}_{2} \mathrm{SO}_{4}$ and evaporated to dryness. Compounds 1-6 and 8 were obtained through recrystallization from n-hexane, Compounds $\mathbf{1 0}$ and $\mathbf{1 1}$ from chloroform and $\mathbf{7}$ and $\mathbf{9}$ were purified by column chromatography over silica gel (eleuent: 40:1 EtOAc- $\mathrm{CH}_{3} \mathrm{OH}$ ).

$N$-Stearoyl-L-phenylalanine (1). Yield 80\%; white solid; m.p. $66-68{ }^{\circ} \mathrm{C} ;[\alpha]_{\mathrm{D}}^{21}:+20.9^{\circ}\left(\mathrm{c} 0.92, \mathrm{CHCl}_{3}\right)$; ${ }^{1} \mathrm{H}-\mathrm{NMR}: \delta$ (ppm) 7.27 (m, 3H of Ph), 7.15 (d, $J=6.6 \mathrm{~Hz}, 2 \mathrm{H}$ of $\left.\mathrm{Ph}\right), 6.07$ (d, 1H, $\left.J=7.3 \mathrm{~Hz}, \mathrm{NH}\right)$, $4.90(\mathrm{t}, 1 \mathrm{H}, J=6.0 \mathrm{~Hz}, \mathrm{CHN}), 3.13-3.23\left(\mathrm{~m}, 2 \mathrm{H}, \mathrm{CH}_{2} \mathrm{Ph}\right), 2.17$ (t, 2H, $\left.J=4 \mathrm{~Hz}, \mathrm{CH}_{2} \mathrm{CON}\right), 1.55$ (m, $\left.2 \mathrm{H}, \mathrm{CH}_{2}\right), 1.25\left(\mathrm{~m}, 28 \mathrm{H}, 14 \times \mathrm{CH}_{2}\right), 0.88\left(\mathrm{t}, 3 \mathrm{H}, J=6.9 \mathrm{~Hz}, \mathrm{CH}_{3}\right) ;{ }^{13} \mathrm{C}-\mathrm{NMR}: \delta(\mathrm{ppm}) 174.6,174.1$ (2C, acid and amide $\mathrm{C}=\mathrm{O}), 135.7(\mathrm{i}-\mathrm{C}$ of $\mathrm{Ph}), 129.3(2 \times \mathrm{o}-\mathrm{CH}$ of $\mathrm{Ph}), 128.6(2 \times \mathrm{m}-\mathrm{CH}$ of $\mathrm{Ph}), 127.2$ ( $p$-CH of $\mathrm{Ph}), 53.1(\mathrm{CHN}), 37.3\left(\mathrm{CH}_{2} \mathrm{Ph}\right), 36.4\left(\mathrm{CH}_{2}\right.$-amide), 33.3( $\left(\mathrm{CH}_{2}\right), 31.9\left(\mathrm{CH}_{2}\right), 29.7-29.2(12 \times$ $\left.\mathrm{CH}_{2}\right), 25.5\left(\mathrm{CH}_{2}\right), 22.6\left(\mathrm{CH}_{2}\right), 14.1\left(\mathrm{CH}_{3}\right)$; ESI-MS: [M-1] $]^{+} \mathrm{m} / \mathrm{z} 430.1$.

N-Stearoyl-DL-phenylalanine (2). Yield 67\%; white solid; m.p. $93-95{ }^{\circ} \mathrm{C} ;[\alpha]_{\mathrm{D}}^{21}: 0^{\circ}\left(c \quad 0.92, \mathrm{CHCl}_{3}\right)$; ${ }^{1} \mathrm{H}-\mathrm{NMR}$ and ${ }^{13} \mathrm{C}-\mathrm{NMR}$ spectra were identical to those of 1; ESI-MS: [M-1] ${ }^{+} \mathrm{m} / \mathrm{z} 430.1$. 
$N$-Stearoyl-L-proline (3). Yield 50\%; white solid; m.p. $87-89{ }^{\circ} \mathrm{C} ;[\alpha]_{\mathrm{D}}^{22}:+32.1^{\circ}\left(c 1.0, \mathrm{CHCl}_{3}\right) ;{ }^{1} \mathrm{H}-$ NMR: $\delta$ (ppm) 4.81-4.66 (m, 5H of pyrrolidine), 3.22 (m, $2 \mathrm{H}$ of pyrrolidine), 2.13 (t, $2 \mathrm{H}, J=3.5 \mathrm{~Hz}$, $\left.\mathrm{CH}_{2} \mathrm{CON}\right), 1.55\left(\mathrm{~m}, 2 \mathrm{H}, \mathrm{CH}_{2}\right), 1.23\left(\mathrm{~m}, 28 \mathrm{H}, 14 \times \mathrm{CH}_{2}\right), 0.89\left(\mathrm{t}, 3 \mathrm{H}, J=7 \mathrm{~Hz}, \mathrm{CH}_{3}\right) ;{ }^{13} \mathrm{C}-\mathrm{NMR}: \delta$ (ppm) 174.7, $174.2\left(2 \times \mathrm{C}=\mathrm{O}\right.$, acid and amide), $61.7(\mathrm{~N}-\mathrm{CH}$ of pyrrolidine $), 53.4\left(\mathrm{~N}-\mathrm{CH}_{2}\right.$ of pyrrolidine), 37.3 $\left(\mathrm{CH}_{2}\right), 36.4\left(\mathrm{CH}_{2}\right.$-amide $), 31.9\left(\mathrm{CH}_{2}\right), 29.7-29.1\left(13 \times \mathrm{CH}_{2}\right), 25.5\left(\mathrm{CH}_{2}\right.$-pyrrolidine $)$, 22.6 ( $\mathrm{CH}_{2}$-pyrrolidine), $14.1\left(\mathrm{CH}_{3}\right)$; ESI-MS: $[\mathrm{M}+\mathrm{Na}]^{+} \mathrm{m} / \mathrm{z} 404.2$.

$N$-Stearoyl-L-tyrosine (4). Yield 50\%; white solid; m.p. $134-136{ }^{\circ} \mathrm{C} ;[\alpha]_{\mathrm{D}}^{18}:+41.7^{\circ}\left(c 1.0, \mathrm{CH}_{3} \mathrm{OH}\right) ;{ }^{1} \mathrm{H}$ NMR: $\delta$ (ppm) 6.99 (d, $J=10.4 \mathrm{~Hz}, 2 \mathrm{H}$ of Ph), $6.73(\mathrm{~d}, J=10.2 \mathrm{~Hz}, 2 \mathrm{H}$ of $\mathrm{Ph}), 5.94(\mathrm{~s}, 1 \mathrm{H}, \mathrm{NH}), 4.82$ (t, $1 \mathrm{H}, J=6.0 \mathrm{~Hz}, \mathrm{CHN}), 3.1\left(\mathrm{~m}, 2 \mathrm{H}, \mathrm{CH}_{2} \mathrm{Ph}\right), 2.17$ (t, $\left.2 \mathrm{H}, J=7.8 \mathrm{~Hz}, \mathrm{CH}_{2} \mathrm{CON}\right), 1.56\left(\mathrm{~m}, 2 \mathrm{H}, \mathrm{CH}_{2}\right)$, $1.26\left(\mathrm{~m}, 28 \mathrm{H}, 14 \times \mathrm{CH}_{2}\right), 0.88\left(\mathrm{t}, 3 \mathrm{H}, J=6.8 \mathrm{~Hz}, \mathrm{CH}_{3}\right) ;{ }^{13} \mathrm{C}-\mathrm{NMR}: \delta(\mathrm{ppm}) 174.1,173.9(2 \times \mathrm{C}=\mathrm{O}$, acid and amide), 155.3 (C-OH of Ph), 133.5(i-C of Ph),130.4 (2 $\times$ o-CH of Ph), $115.8(2 \times m-\mathrm{CH}$ of $\mathrm{Ph}), 53.4(\mathrm{CHN}), 36.8\left(\mathrm{CH}_{2} \mathrm{Ph}\right), 36.5\left(\mathrm{CH}_{2}\right.$-amide $), 31.9\left(\mathrm{CH}_{2}\right), 31.5\left(\mathrm{CH}_{2}\right), 29.7-29.2\left(12 \times \mathrm{CH}_{2}\right), 25.6$ $\left(\mathrm{CH}_{2}\right), 22.6\left(\mathrm{CH}_{2}\right), 14.0\left(\mathrm{CH}_{3}\right)$; ESI-MS: $[\mathrm{M}+1]^{+} \mathrm{m} / \mathrm{z} 448.2$.

$N$-stearoyl-L-serine (5). Yield 60\%; white solid; m.p. 100-102 ${ }^{\circ} \mathrm{C} ;[\alpha]_{\mathrm{D}}^{19}:+21.2^{\circ}\left(\mathrm{c} 1.0, \mathrm{CH}_{3} \mathrm{OH}\right) ;{ }^{1} \mathrm{H}$ NMR $\left(\mathrm{CD}_{3} \mathrm{OD}\right): \delta(\mathrm{ppm}) 4.48(\mathrm{t}, 1 \mathrm{H}, J=4.4 \mathrm{~Hz}, \mathrm{~N}-\mathrm{CH}), 3.86\left(\mathrm{~m}, 2 \mathrm{H}, \mathrm{CH}_{2} \mathrm{O}\right), 2.26(\mathrm{t}, 2 \mathrm{H}, J=7.4 \mathrm{~Hz}$, $\left.\mathrm{CH}_{2} \mathrm{CON}\right), 1.62\left(\mathrm{~m}, 2 \mathrm{H}, \mathrm{CH}_{2}\right), 1.28\left(\mathrm{~m}, 28 \mathrm{H}, 14 \times \mathrm{CH}_{2}\right), 0.89\left(\mathrm{t}, 3 \mathrm{H}, J=6.8 \mathrm{~Hz}, \mathrm{CH}_{3}\right) ;{ }^{13} \mathrm{C}-\mathrm{NMR}$ $\left(\mathrm{CD}_{3} \mathrm{OD}\right): \delta(\mathrm{ppm})$ 176.7, $173.8\left(2 \times \mathrm{C}=\mathrm{O}\right.$, acid and amide), $63.3\left(\mathrm{CH}_{2} \mathrm{O}\right), 56.3(\mathrm{CHN}), 37.2\left(\mathrm{CH}_{2}-\right.$ amide), $33.3\left(\mathrm{CH}_{2}\right), 31.1-30.6\left(12 \times \mathrm{CH}_{2}\right), 27.1\left(\mathrm{CH}_{2}\right), 24.0\left(\mathrm{CH}_{2}\right), 14.7\left(\mathrm{CH}_{3}\right) ; \mathrm{ESI}-\mathrm{MS}:[\mathrm{M}+1]^{+} \mathrm{m} / \mathrm{z}$ 372.1 .

$N$-Stearoyl-L-threonine (6). Yield 56\%; white solid; m.p. $62-64{ }^{\circ} \mathrm{C} ;[\alpha]_{\mathrm{D}}^{22}:+12.5^{\circ}\left(\mathrm{c} 0.92, \mathrm{CH}_{3} \mathrm{OH}\right)$; ${ }^{1} \mathrm{H}-\mathrm{NMR}\left(\mathrm{CD}_{3} \mathrm{OD}\right): \delta(\mathrm{ppm}) 6.8(\mathrm{~s}, 1 \mathrm{H}, \mathrm{NH}), 4.51(\mathrm{~d}, 1 \mathrm{H}, J=7.8 \mathrm{~Hz}, \mathrm{CHN}), 4.43(\mathrm{~s}, 1 \mathrm{H}, \mathrm{CHO}), 2.3(\mathrm{t}$, $\left.2 \mathrm{H}, J=7.4 \mathrm{~Hz}, \mathrm{CH}_{2} \mathrm{CON}\right), 1.63\left(\mathrm{~d}, 2 \mathrm{H}, J=6.7 \mathrm{~Hz}, \mathrm{CH}_{2}\right), 1.25\left(\mathrm{~m}, 28 \mathrm{H}, 14 \times \mathrm{CH}_{2}\right), 1.21(\mathrm{~d}, 3 \mathrm{H}, J=$ $\left.6.0 \mathrm{~Hz}, \mathrm{CH}_{3}\right), 0.88\left(\mathrm{dd}, 3 \mathrm{H}, J_{1}=6.7, J_{2}=7.0 \mathrm{~Hz}, \mathrm{CH}_{3}\right) ;{ }^{13} \mathrm{C}-\mathrm{NMR}\left(\mathrm{CD}_{3} \mathrm{OD}\right): \delta(\mathrm{ppm}) 177.2,174.1(2 \times$ $\mathrm{C}=\mathrm{O}$, acid and amide), $66.5(\mathrm{CHO}), 59.6(\mathrm{CHN}), 36.9\left(\mathrm{CH}_{2}\right.$-amide $), 34.2\left(\mathrm{CH}_{2}\right), 30.3-29.6(12 \times$ $\left.\mathrm{CH}_{2}\right), 26.1\left(\mathrm{CH}_{2}\right), 23.3\left(\mathrm{CH}_{2}\right), 17.5\left(\mathrm{CH}_{3}\right), 14.1\left(\mathrm{CH}_{3}\right)$; ESI-MS: $[\mathrm{M}+1]^{+} \mathrm{m} / \mathrm{z} 389.2$.

$N$-Stearoyl-L-tryptophan (7). Yield 30\%; brown solid; m.p. 88-90 ${ }^{\circ} \mathrm{C} ;[\alpha]_{\mathrm{D}}^{20}:+28^{\circ}\left(\mathrm{c} 1.0, \mathrm{CHCl}_{3}\right)$; ${ }^{1} \mathrm{HNMR}: \delta(\mathrm{ppm}) 8.37$ (s, 1H, NH of indole), $7.54(\mathrm{~d}, 1 \mathrm{H}, J=7.8 \mathrm{~Hz}, \mathrm{~N}-\mathrm{CH}$ of indole), 7.3-6.96 (m, 4H, Ph-H of indole), 6.14 (d, 1H, J=7.6 Hz, NH), $4.93(\mathrm{~m}, 1 \mathrm{H}, \mathrm{CHN}), 3.32\left(\mathrm{~m}, 2 \mathrm{H}, \mathrm{CH}_{2}\right.$-indole), 2.07 (t, $\left.2 \mathrm{H}, J=7.4 \mathrm{~Hz}, \mathrm{CH}_{2} \mathrm{CON}\right), 1.48\left(\mathrm{~m}, 2 \mathrm{H}, \mathrm{CH}_{2}\right), 1.25\left(\mathrm{~m}, 28 \mathrm{H}, 14 \times \mathrm{CH}_{2}\right), 0.88(\mathrm{t}, 3 \mathrm{H}, J=7 \mathrm{~Hz}$, $\left.\mathrm{CH}_{3}\right)$; ${ }^{13} \mathrm{CNMR}: \delta$ (ppm) 175.1, $174.3(2 \times \mathrm{C}=\mathrm{O}$, acid and amide), 136.1 (N-C of indole), $127.8(\mathrm{C}$, indole), 123.2 ( $\mathrm{N}-\mathrm{CH}$ of indole), $122.2,119.7$ ( $2 \times \mathrm{CH}, \mathrm{Ph}$ of indole $), 118.4$ (C of indole), 111.4, $109.5\left(2 \times \mathrm{CH}\right.$, Ph of indole), $53.3(\mathrm{CHN}), 36.4\left(\mathrm{CH}_{2}\right.$-amide $), 31.9\left(\mathrm{CH}_{2}\right.$-indole $), 29.7-27.1\left(13 \times \mathrm{CH}_{2}\right)$, $25.4\left(\mathrm{CH}_{2}\right), 22.6\left(\mathrm{CH}_{2}\right), 14.1\left(\mathrm{CH}_{3}\right)$; ESI-MS: $[\mathrm{M}+1]^{+} \mathrm{m} / \mathrm{z} 471.2$.

$N$-Stearoyl-L-leucine (8). Yield 49\%; white solid; m.p. 95-97 ${ }^{\circ} \mathrm{C} ;[\alpha]_{\mathrm{D}}^{20}:-10.3^{\circ}\left(c 1.0, \mathrm{CHCl}_{3}\right) ;{ }^{1} \mathrm{H}-$ NMR: $\delta(\mathrm{ppm}) 5.9(\mathrm{~m}, 1 \mathrm{H}, \mathrm{NH}), 4.62(\mathrm{~m}, 1 \mathrm{H}, \mathrm{CHN}), 2.23\left(\mathrm{t}, 2 \mathrm{H}, J=7.5 \mathrm{~Hz}, \mathrm{CH}_{2} \mathrm{CON}\right), 1.72(\mathrm{~m}, 2 \mathrm{H}$, $\left.\mathrm{CH}_{2}\right), 1.62\left(\mathrm{~m}, 2 \mathrm{H}, \mathrm{CH}_{2}\right), 1.60(\mathrm{~m}, 1 \mathrm{H}, \mathrm{CH}), 1.27\left(\mathrm{~m}, 28 \mathrm{H}, 14 \times \mathrm{CH}_{2}\right), 0.95(\mathrm{~d}, 6 \mathrm{H}, J=4.3 \mathrm{~Hz}$, $\left.2 \times \mathrm{CH}_{3}\right), 0.88\left(\mathrm{t}, 3 \mathrm{H}, J=7 \mathrm{~Hz}, \mathrm{CH}_{3}\right) ;{ }^{13} \mathrm{C}-\mathrm{NMR}: \delta(\mathrm{ppm}) 176.1,174.1(2 \times \mathrm{C}=\mathrm{O}$, acid and amide), 50.9 
$(\mathrm{CHN}), 36.5\left(\mathrm{CH}_{2}\right.$-amide), $31.9\left(\mathrm{CH}_{2}\right), 29.7-29.2\left(13 \times \mathrm{CH}_{2}\right), 25.6\left(\mathrm{CH}_{2}\right), 24.9\left(\mathrm{CH}_{2}\right), 22.8(\mathrm{CH}), 22.6$ $\left(\mathrm{CH}_{3}\right), 21.9\left(\mathrm{CH}_{3}\right), 14.1\left(\mathrm{CH}_{3}\right)$; ESI-MS: [M-1] $]^{+} \mathrm{m} / \mathrm{z} 396.1$.

$N$-Stearoyl-L-cysteine (9). Yield 30\%; white solid; m.p. $146-148{ }^{\circ} \mathrm{C} ;[\alpha]_{\mathrm{D}}^{20}:+35.4^{\circ}\left(\mathrm{c} 1.0, \mathrm{CH}_{3} \mathrm{OH}\right)$; ${ }^{1} \mathrm{HNMR}\left(\mathrm{CD}_{3} \mathrm{OD}\right): \delta(\mathrm{ppm}) 4.67(\mathrm{~m}, 1 \mathrm{H}, \mathrm{CHN}), 3.63\left(\mathrm{~m}, 2 \mathrm{H}, \mathrm{CH}_{2} \mathrm{~S}\right), 2.25(\mathrm{t}, 2 \mathrm{H}, J=7.2 \mathrm{~Hz}$, $\left.\mathrm{CH}_{2} \mathrm{CON}\right), 1.62\left(\mathrm{~m}, 2 \mathrm{H}, \mathrm{CH}_{2}\right), 1.28\left(\mathrm{~m}, 28 \mathrm{H}, 14 \times \mathrm{CH}_{2}\right), 0.89\left(\mathrm{t}, 3 \mathrm{H}, J=6.8 \mathrm{~Hz}, \mathrm{CH}_{3}\right) ;{ }^{13} \mathrm{CNMR}$ $\left(\mathrm{CD}_{3} \mathrm{OD}\right): \delta(\mathrm{ppm})$ 176.5, $173.8(2 \times \mathrm{C}=\mathrm{O}$, acid and amide $), 50.1(\mathrm{CHN}), 37.3\left(\mathrm{CH}_{2}\right.$-amide $), 33.3$ $\left(\mathrm{CH}_{2} \mathrm{~S}\right), 31.1-30.6\left(13 \times \mathrm{CH}_{2}\right), 27.2\left(\mathrm{CH}_{2}\right), 24.0\left(\mathrm{CH}_{2}\right), 14.7\left(\mathrm{CH}_{3}\right)$; ESI-MS: $[\mathrm{M}+1]^{+} \mathrm{m} / \mathrm{z} 388.0$.

$N$-Stearoyl-L-histidine (10). Yield 56\%; white solid; m.p. $127-129{ }^{\circ} \mathrm{C} ;[\alpha]_{\mathrm{D}}^{22}:+5.9^{\circ}\left(\mathrm{c} 1.0, \mathrm{CH}_{3} \mathrm{OH}\right)$; ${ }^{1} \mathrm{H}-\mathrm{NMR}$ (CD $\mathrm{CD}_{3} \mathrm{OD}$ ): $\delta$ (ppm) 8.46, 7.12 (m, 2H of imidazole), $4.5(\mathrm{~m}, 1 \mathrm{H}, \mathrm{CHN}), 3.04-3.22(\mathrm{~m}, 2 \mathrm{H}$, $\mathrm{CH}_{2}$-imidazole), 2.19 (t, $\left.2 \mathrm{H}, J=6 \mathrm{~Hz}, \mathrm{CH}_{2} \mathrm{CON}\right), 1.51\left(\mathrm{~m}, 2 \mathrm{H}, \mathrm{CH}_{2}\right), 1.28\left(\mathrm{~m}, 28 \mathrm{H}, 14 \times \mathrm{CH}_{2}\right), 0.89$ $\left(\mathrm{t}, 3 \mathrm{H}, J=6.9 \mathrm{~Hz}, \mathrm{CH}_{3}\right) .{ }^{13} \mathrm{C}-\mathrm{NMR}\left(\mathrm{CD}_{3} \mathrm{OD}\right): \delta(\mathrm{ppm}) 176.1,174.9(2 \times \mathrm{C}=\mathrm{O}$, acid and amide $), 135.1$ ( N-CH of imidazole), 133.1 (N-C of imidazole), $118.5\left(\mathrm{NH}-\mathrm{CH}\right.$ of imidazole), $54.6(\mathrm{CHN}), 37.4\left(\mathrm{CH}_{2}-\right.$ amide), $33.4\left(\mathrm{CH}_{2}\right.$-imidazole), 31.1-29.7 $\left(13 \times \mathrm{CH}_{2}\right), 27.2\left(\mathrm{CH}_{2}\right), 24.0\left(\mathrm{CH}_{2}\right), 14.7\left(\mathrm{CH}_{3}\right)$; ESI-MS: $[\mathrm{M}+1]^{+} \mathrm{m} / \mathrm{z} 422.1$.

$N$-Stearoyl-L-lysine (11). Yield 50\%; white solid; m.p. 85-87 ${ }^{\circ} \mathrm{C} ;[\alpha]_{\mathrm{D}}^{20}:-28.3^{\circ}\left(\mathrm{c} 1.0, \mathrm{CH}_{3} \mathrm{OH}\right) ;{ }^{1} \mathrm{H}$ NMR (CD $\left.{ }_{3} \mathrm{OD}\right): \delta(\mathrm{ppm}) 4.19(\mathrm{~m}, 1 \mathrm{H}, \mathrm{CHN}), 3.17\left(\mathrm{~m}, 2 \mathrm{H}, \mathrm{CH}_{2} \mathrm{~N}\right), 2.51\left(\mathrm{~m}, 2 \mathrm{H}, \mathrm{CH}_{2} \mathrm{CON}\right), 1.71(\mathrm{~m}$, $\left.2 \mathrm{H}, \mathrm{CH}_{2}\right), 1.56\left(2 \times \mathrm{CH}_{2}\right), 1.28\left(\mathrm{~m}, 30 \mathrm{H}, 15 \times \mathrm{CH}_{2}\right), 0.89\left(\mathrm{t}, 3 \mathrm{H}, J=6.8 \mathrm{~Hz}, \mathrm{CH}_{3}\right) ;{ }^{13} \mathrm{C}-\mathrm{NMR}$ $\left(\mathrm{CD}_{3} \mathrm{OD}\right): \delta(\mathrm{ppm}) 170.3,168.8(2 \times \mathrm{C}=\mathrm{O}$, acid and amide $), 48.3(\mathrm{CHN}), 31.6\left(\mathrm{CH}_{2} \mathrm{NH}_{2}\right), 30.1\left(\mathrm{CH}_{2}-\right.$ amide), 29.2-28.7 $\left(15 \times \mathrm{CH}_{2}\right), 28.3\left(\mathrm{CH}_{2}\right), 24.5\left(\mathrm{CH}_{2}\right), 22.2\left(\mathrm{CH}_{2}\right), 14.0\left(\mathrm{CH}_{3}\right) ; \mathrm{ESI}-\mathrm{MS}:[\mathrm{M}-1]^{+} \mathrm{m} / \mathrm{z}$ 411.2.

3.2.2. Synthesis and spectroscopic data of $\mathrm{N}$-stearoylamino acid methyl esters 12-14

A mixture of the appropriate amino acid methyl ester $(6.3 \mathrm{mmol})$ and octadecanoic acid 2,5-dioxopyrrolidin-1-yl ester $(7 \mathrm{mmol})$ in dry pyridine $(50 \mathrm{~mL})$ was stirred at room temperature for $24 \mathrm{~h}$. After evaporation of solvent, the residue was dissolved in dichloromethane $(100 \mathrm{~mL})$, and washed with $\mathrm{HCl}$ $(1 \mathrm{M}, 100 \mathrm{~mL} \times 2)$, water $(100 \mathrm{~mL}), 5 \% \mathrm{NaHCO}_{3}(100 \mathrm{~mL})$ and saturated $\mathrm{NaCl}(100 \mathrm{~mL} \times 2)$. The organic layer was dried over anhydr. $\mathrm{Na}_{2} \mathrm{SO}_{4}$. After filtration and evaporation of the solvent in vacuo, the crude product was purified by recrystallization from methanol-chloroform.

$N$-Stearoylglycine methyl ester (12). Yield $24 \%$; white solid; m.p. $82-84{ }^{\circ} \mathrm{C} ;[\alpha]_{\mathrm{D}}^{20}: 0^{\circ}\left(c 1.0, \mathrm{CHCl}_{3}\right)$; ${ }^{1} \mathrm{H}-\mathrm{NMR}: \delta(\mathrm{ppm}) 5.97(\mathrm{~m}, 1 \mathrm{H}, \mathrm{NH}), 4.04\left(\mathrm{~d}, 2 \mathrm{H}, J=5.1 \mathrm{~Hz}, \mathrm{CH}_{2} \mathrm{~N}\right), 3.75\left(\mathrm{~s}, 3 \mathrm{H}, \mathrm{CH}_{3} \mathrm{O}\right), 2.23(\mathrm{t}, 2 \mathrm{H}$, $\left.J=7.5 \mathrm{~Hz}, \mathrm{CH}_{2} \mathrm{CON}\right), 1.62\left(\mathrm{~m}, 2 \mathrm{H}, \mathrm{CH}_{2}\right), 1.26\left(\mathrm{~m}, 28 \mathrm{H}, 14 \times \mathrm{CH}_{2}\right), 0.87\left(\mathrm{t}, 3 \mathrm{H}, J=7 \mathrm{~Hz}, \mathrm{CH}_{3}\right) ;{ }^{13} \mathrm{C}-$ NMR: $\delta(\mathrm{ppm}) 173.4,170.7(2 \times \mathrm{C}=\mathrm{O}$, acid methyl ester and amide $), 52.4\left(\mathrm{CH}_{3} \mathrm{O}\right), 41.3\left(\mathrm{CH}_{2} \mathrm{~N}\right), 36.5$ $\left(\mathrm{CH}_{2}\right.$-amide), $31.9\left(\mathrm{CH}_{2}\right), 29.7-29.3\left(12 \times \mathrm{CH}_{2}\right), 25.6\left(\mathrm{CH}_{2}\right), 22.8\left(\mathrm{CH}_{2}\right), 14.1\left(\mathrm{CH}_{3}\right)$; ESI-MS: $[\mathrm{M}+1]^{+}$ $\mathrm{m} / \mathrm{z} 356.1$

$N$-Stearoyl-L-glutamic acid dimethyl ester (13). Yield 23\%; white solid; m.p. 85-87 ${ }^{\circ} \mathrm{C} ;[\alpha]_{\mathrm{D}}^{19}:+18^{\circ}(\mathrm{c}$ 1.2, $\left.\mathrm{CHCl}_{3}\right) ;{ }^{1} \mathrm{H}-\mathrm{NMR}: \delta$ (ppm) $6.15(\mathrm{~d}, 1 \mathrm{H}, J=7.4 \mathrm{~Hz}, \mathrm{NH}), 4.64(\mathrm{~m}, 1 \mathrm{H}, \mathrm{CHN}), 3.77,3.68(\mathrm{~s}, 6 \mathrm{H}, 2$ $\left.\times \mathrm{CH}_{3} \mathrm{O}\right), 2.39\left(\mathrm{~m}, 2 \mathrm{H}, \mathrm{CH}_{2}\right), 2.21\left(\mathrm{t}, 2 \mathrm{H}, \mathrm{J}=7.4 \mathrm{~Hz}, \mathrm{CH}_{2} \mathrm{COO}\right), 2.11\left(\mathrm{~m}, 2 \mathrm{H}, \mathrm{CH}_{2} \mathrm{CON}\right), 1.62(\mathrm{t}, 2 \mathrm{H}$, 
$\left.\mathrm{CH}_{2}\right), 1.28\left(\mathrm{~m}, 28 \mathrm{H}, 14 \times \mathrm{CH}_{2}\right), 0.88\left(\mathrm{t}, 3 \mathrm{H}, \mathrm{J}=6.8 \mathrm{~Hz}, \mathrm{CH}_{3}\right) ;{ }^{13} \mathrm{C}-\mathrm{NMR}: \delta(\mathrm{ppm}) 173.3,173.1,172.5$ $\left(3 \times \mathrm{C}=\mathrm{O}\right.$, acid methyl ester and amide), $52.5(\mathrm{CHN}), 51.8,51.5\left(2 \times \mathrm{CH}_{3} \mathrm{O}\right), 36.6\left(\mathrm{CH}_{2}\right.$-amide $), 31.9$ $\left(\mathrm{CH}_{2}\right.$-acid), $30.1\left(\mathrm{CH}_{2}\right), 29.7-29.2\left(12 \times \mathrm{CH}_{2}\right), 27.4\left(\mathrm{CH}_{2}\right), 25.6\left(\mathrm{CH}_{2}\right), 22.7\left(\mathrm{CH}_{2}\right), 14.1\left(\mathrm{CH}_{3}\right)$; ESIMS: $[\mathrm{M}+\mathrm{H}]^{+} \mathrm{m} / \mathrm{z} 442.2$.

$N$-Stearoyl-L-phenylalanine methyl ester (14). Yield 30\%; grey solid; m.p. $70-72{ }^{\circ} \mathrm{C} ;[\alpha]_{\mathrm{D}}^{22}:-16.7^{\circ}(\mathrm{C}$ 1.0, $\left.\mathrm{CHCl}_{3}\right)$; ${ }^{1} \mathrm{H}-\mathrm{NMR}: \delta(\mathrm{ppm}) 7.28\left(\mathrm{~m}, 3 \mathrm{H}\right.$ of Ph), $7.12\left(\mathrm{dd}, J_{1}=1.5, J_{2}=6.7 \mathrm{~Hz}, 2 \mathrm{H}\right.$ of Ph), $5.89(\mathrm{~d}$, $1 \mathrm{H}, J=7.6 \mathrm{~Hz}, \mathrm{NH}), 4.92(\mathrm{~m}, 1 \mathrm{H}, \mathrm{CHN}), 3.75\left(\mathrm{~s}, 3 \mathrm{H}, \mathrm{CH}_{3} \mathrm{O}\right), 3.13\left(\mathrm{~m}, 2 \mathrm{H}, \mathrm{CH}_{2} \mathrm{Ph}\right), 2.18(\mathrm{t}, 2 \mathrm{H}, J=$ $\left.6.8 \mathrm{~Hz}, \mathrm{CH}_{2} \mathrm{CON}\right), 1.63\left(\mathrm{~m}, 2 \mathrm{H}, \mathrm{CH}_{2}\right), 1.29\left(\mathrm{~m}, 28 \mathrm{H}, 14 \times \mathrm{CH}_{2}\right), 0.90\left(\mathrm{t}, 3 \mathrm{H}, J=7 \mathrm{~Hz}, \mathrm{CH}_{3}\right) ;{ }^{13} \mathrm{C}-$ NMR: $\delta$ (ppm) 173.7, $172.3(2 \times \mathrm{C}=\mathrm{O}$, acid methyl ester and amide $), 137.6(\mathrm{i}-\mathrm{C}$ of $\mathrm{Ph}), 129.2\left(2 \times o_{-}\right.$ $\mathrm{CH}$ of $\mathrm{Ph}), 128.6(2 \times m-\mathrm{CH}$ of $\mathrm{Ph}), 126.6(p-\mathrm{CH}$ of $\mathrm{Ph}), 64.3(\mathrm{CHN}), 52.8\left(\mathrm{CH}_{3} \mathrm{O}\right), 37.0\left(\mathrm{CH}_{2} \mathrm{Ph}\right)$, $36.8\left(\mathrm{CH}_{2}\right.$-amide), $31.9\left(\mathrm{CH}_{2}\right), 29.7-29.1\left(12 \times \mathrm{CH}_{2}\right), 25.7\left(\mathrm{CH}_{2}\right), 22.7\left(\mathrm{CH}_{2}\right), 14.2\left(\mathrm{CH}_{3}\right)$; ESI-MS: $[\mathrm{M}+1]^{+} \mathrm{m} / \mathrm{z} 446.3$.

\subsubsection{Synthesis and spectroscopic data of $N$-palmitoyl-L-tyrosine (15)}

Hexadecanoic acid 2,5-dioxo-pyrrolidin-1-yl ester was synthesized following the synthetic route of octadecanoic acid 2,5-dioxo-pyrrolidin-1-yl ester from palmitic acid instead of stearic acid. Then 15 was prepared from hexadecanoic acid 2,5-dioxo-pyrrolidin-1-yl ester instead of octadecanoic acid 2,5dioxo-pyrrolidin-1-yl ester by the same procedure of 1-11. Yield 45\%; white solid; recrystallization from n-hexane; m.p. $115-117^{\circ} \mathrm{C} ;[\alpha]_{\mathrm{D}}^{22}:+24.2^{\circ}\left(c\right.$ 1.0, $\left.\mathrm{CH}_{3} \mathrm{OH}\right) ;{ }^{1} \mathrm{H}-\mathrm{NMR}\left(\mathrm{CD}_{3} \mathrm{OD}\right): \delta(\mathrm{ppm}) 7.03(\mathrm{~m}$, $2 \mathrm{H}$ of $\mathrm{Ph}), 6.73(\mathrm{~m}, 2 \mathrm{H}$ of $\mathrm{Ph}), 4.62(\mathrm{~m}, 1 \mathrm{H}, \mathrm{CHN}), 2.8-3.09\left(\mathrm{~m}, 2 \mathrm{H}, \mathrm{CH}_{2} \mathrm{Ph}\right), 2.15(\mathrm{t}, 2 \mathrm{H}, J=7.5 \mathrm{~Hz}$, $\left.\mathrm{CH}_{2} \mathrm{CON}\right), 1.48\left(\mathrm{~m}, 2 \mathrm{H}, \mathrm{CH}_{2}\right), 1.28\left(\mathrm{~m}, 24 \mathrm{H}, 12 \times \mathrm{CH}_{2}\right), 0.89\left(\mathrm{t}, 3 \mathrm{H}, \mathrm{J}=7 \mathrm{~Hz}, \mathrm{CH}_{3}\right) ;{ }^{13} \mathrm{C}-\mathrm{NMR}$ $\left(\mathrm{CD}_{3} \mathrm{OD}\right): \delta(\mathrm{ppm}) 176.4,175.3(2 \times \mathrm{C}=\mathrm{O}$, acid and amide), $157.6(\mathrm{C}-\mathrm{OH}$ of $\mathrm{Ph}), 131.5(\mathrm{i}-\mathrm{C}$ of $\mathrm{Ph})$, 129.4, $122.8(2 \times o-\mathrm{CH}$ of $\mathrm{Ph}), 116.6(2 \times \mathrm{m}-\mathrm{CH}$ of $\mathrm{Ph}), 55.4(\mathrm{CHN}), 37.9\left(\mathrm{CH}_{2} \mathrm{Ph}\right), 37.1\left(\mathrm{CH}_{2}\right.$-amide $)$, 33.4 $\left(\mathrm{CH}_{2}\right), 31.1-30.4\left(10 \times \mathrm{CH}_{2}\right), 27.2\left(\mathrm{CH}_{2}\right), 24.0\left(\mathrm{CH}_{2}\right), 14.7\left(\mathrm{CH}_{3}\right)$; ESI-MS: $[\mathrm{M}+1]^{+} \mathrm{m} / \mathrm{z} 420.1$.

\subsubsection{Synthesis and spectroscopic data of N-lauroyl-L-tyrosine (16)}

Dodecanoic acid 2,5-dioxo-pyrrolidin-1-yl ester was synthesized following the synthetic route of octadecanoic acid 2,5-dioxo-pyrrolidin-1-yl ester from lauric acid instead of stearic acid. Then $\mathbf{1 6}$ was prepared from dodecanoic acid 2,5-dioxo-pyrrolidin-1-yl ester instead of octadecanoic acid 2,5-dioxopyrrolidin-1-yl ester by the same procedure of 1-11. Yield 50\%; white solid; recrystallization from $n$ hexane; m.p. $95-97{ }^{\circ} \mathrm{C} ;[\alpha]_{\mathrm{D}}^{22}:+17.4^{\circ}\left(\mathrm{c} 1.0, \mathrm{CH}_{3} \mathrm{OH}\right) ;{ }^{1} \mathrm{H}-\mathrm{NMR}\left(\mathrm{CD}_{3} \mathrm{OD}\right): \delta(\mathrm{ppm}) 6.99(\mathrm{~m}, 2 \mathrm{H}$ of $\mathrm{Ph}), 6.73(\mathrm{~m}, 2 \mathrm{H}$ of $\mathrm{Ph}), 4.62(\mathrm{~m}, 1 \mathrm{H}, \mathrm{CHN}), 2.8-3.09\left(\mathrm{~m}, 2 \mathrm{H}, \mathrm{CH}_{2} \mathrm{Ph}\right), 2.14(\mathrm{t}, 2 \mathrm{H}, J=7.5 \mathrm{~Hz}$, $\left.\mathrm{CH}_{2} \mathrm{CON}\right), 1.48\left(\mathrm{~m}, 2 \mathrm{H}, \mathrm{CH}_{2}\right), 1.27\left(\mathrm{~m}, 16 \mathrm{H}, 8 \times \mathrm{CH}_{2}\right), 0.88\left(\mathrm{t}, 3 \mathrm{H}, J=6.8 \mathrm{~Hz}, \mathrm{CH}_{3}\right) ;{ }^{13} \mathrm{C}-\mathrm{NMR}$ $\left(\mathrm{CD}_{3} \mathrm{OD}\right): \delta(\mathrm{ppm})$ 176.6, 175.4 (2C, acid and amide $\left.\mathrm{C}=\mathrm{O}\right), 157.8(\mathrm{C}-\mathrm{OH}$ of $\mathrm{Ph}), 131.7$ (i-C of $\left.\mathrm{Ph}\right)$, 129.6, $123.1(2 \times o-\mathrm{CH}$ of $\mathrm{Ph}), 116.6(2 \times m-\mathrm{CH}$ of $\mathrm{Ph}), 55.6(\mathrm{CHN}), 38.2\left(\mathrm{CH}_{2} \mathrm{Ph}\right), 37.3\left(\mathrm{CH}_{2}\right.$-amide $)$, 33.6 $\left(\mathrm{CH}_{2}\right), 31.3-30.6\left(6 \times \mathrm{CH}_{2}\right), 27.3\left(\mathrm{CH}_{2}\right), 24.2\left(\mathrm{CH}_{2}\right), 14.9\left(\mathrm{CH}_{3}\right)$; ESI-MS: $[\mathrm{M}+\mathrm{H}]^{+} \mathrm{m} / \mathrm{z}$ 364.0. 


\subsubsection{Synthesis and spectroscopic data of $N$-stearoyl-L-tyrosinol (17)}

To L-tyyrosine (1.81 g, $10 \mathrm{mmol})$ and $\mathrm{NaBH}_{4}(0.91 \mathrm{~g}, 24 \mathrm{mmol})$ dissolved in THF (50 ml) were added dropwise $\mathrm{I}_{2}(2.54 \mathrm{~g}, 10 \mathrm{mmol})$ in THF $(7.5 \mathrm{~mL})$ during $10 \mathrm{~min}$. Then, the mixture was refluxed for $5 \mathrm{~h}$. It was then cooled to room temperature, and $\mathrm{MeOH}(5 \mathrm{~mL})$ was added. The solvent was evaporated and the residue dissolved in $2 \mathrm{M} \mathrm{HCl}(10 \mathrm{~mL})$. After removal of the solvent in vacuo, the residue was then suspended in $\mathrm{EtOH}(30 \mathrm{~mL})$ at $40{ }^{\circ} \mathrm{C}$ and the suspension filtered. The filtrate was concentrated until crystals appear and was kept at $5{ }^{\circ} \mathrm{C}$ overnight. The resulting crystals were isolated by filtration, washed with $\mathrm{EtOH}$, and dried in vacuo to yield $45 \%$ of L-tyrosinol hydriodide as colorless crystals: m.p. $214-216^{\circ} \mathrm{C}$. Then 17 was prepared from L-tyrosinol hydriodide instead of L-tyrosine by the same procedure of 1-11. Yield 30\%; white solid; recrystallization from n-hexane; m.p. 121-123 ${ }^{\circ} \mathrm{C}$; $[\alpha]_{\mathrm{D}}^{22}:+27.1^{\circ}\left(\mathrm{c} 1.0, \mathrm{CH}_{3} \mathrm{OH}\right) ;{ }^{1} \mathrm{H}-\mathrm{NMR}: \delta(\mathrm{ppm}) 7.28(\mathrm{~m}, 2 \mathrm{H}$ of $\mathrm{Ph}), 7.22(\mathrm{~m}, 2 \mathrm{H}$ of Ph$), 5.78(\mathrm{~d}, 1 \mathrm{H}$, $J=7.6 \mathrm{~Hz}, \mathrm{NH}), 4.17(\mathrm{~m}, 1 \mathrm{H}, \mathrm{CHN}), 3.66-3.58\left(\mathrm{~m}, 2 \mathrm{H}, \mathrm{CH}_{2} \mathrm{O}\right), 2.86\left(\mathrm{~m}, 2 \mathrm{H}, \mathrm{CH}_{2} \mathrm{Ph}\right), 2.12(\mathrm{t}, 2 \mathrm{H}, J=$ $\left.7.5 \mathrm{~Hz}, \mathrm{CH}_{2} \mathrm{CON}\right), 1.53\left(\mathrm{~m}, 2 \mathrm{H}, \mathrm{CH}_{2}\right), 1.25\left(\mathrm{~m}, 28 \mathrm{H}, 14 \times \mathrm{CH}_{2}\right), 0.88\left(\mathrm{t}, 3 \mathrm{H}, J=7.1 \mathrm{~Hz}, \mathrm{CH}_{3}\right) ;{ }^{13} \mathrm{C}-$ NMR: $\delta$ (ppm) $173.9(\mathrm{CONH}), 155.6(\mathrm{C}-\mathrm{OH}$ of $\mathrm{Ph}), 137.7$ (i-C of $\mathrm{Ph}), 129.1,128.6(2 \times$ o-CH of Ph), $126.6(2 \times m-\mathrm{CH}$ of $\mathrm{Ph}), 63.3\left(\mathrm{CH}_{2} \mathrm{OH}\right), 52.8(\mathrm{CHN}), 37.0\left(\mathrm{CH}_{2} \mathrm{Ph}\right), 36.8\left(\mathrm{CH}_{2}\right.$-amide $), 31.9\left(\mathrm{CH}_{2}\right)$, 29.7-29.1 (12× $\left.\mathrm{CH}_{2}\right), 25.7\left(\mathrm{CH}_{2}\right), 22.7\left(\mathrm{CH}_{2}\right), 14.1\left(\mathrm{CH}_{3}\right)$; ESI-MS: $[\mathrm{M}+\mathrm{H}]^{+} \mathrm{m} / \mathrm{z}$ 434.3.

\subsection{Neuroprotective effects of the target compounds on rat brain slices in vitro injury models}

The slices were prepared as described by Bickler with modification [26]. Whole brain from male Sprague-Dawley rats (about $100 \mathrm{~g} \pm 50 \mathrm{~g}$ ) were obtained after decapitation and quickly removed to ice-cold oxygenated $\left(95 \% \mathrm{O}_{2} / 5 \% \mathrm{CO}_{2}\right)$ normal artificial cerebrospinal fluid (ACSF), which had the following composition (in $\mathrm{mM}$ ): $\mathrm{NaCl} 119, \mathrm{KCl} 2.5, \mathrm{CaCl}_{2} 2, \mathrm{MgSO}_{4} 1, \mathrm{NaH}_{2} \mathrm{PO}_{4}$ 1.25, $\mathrm{NaHCO}_{3} 26.2$, glucose10 (final $\mathrm{pH}$ 7.4). Brain slices (400 $\mu \mathrm{m}$ thick) were prepared using a vibrating tissue slicer (ZQP-86, Xiangshan, Zhejiang, China), then transferred to a 'slice saver' containing continuouslyoxygenated normal ACSF at 32-34 ${ }^{\circ} \mathrm{C}$ for 90 min recover. After that, brain slices were transferred to experimental chambers and randomly assigned to one of following groups: control group, in which slices were immersed in oxygenated ACSF at $34{ }^{\circ} \mathrm{C}$; OGD group, in which slices were made anoxic by switching the ACSF into the glucose-free ACSF equilibrated with $95 \% \mathrm{~N}_{2} / 5 \% \mathrm{CO}_{2}$. After 10 min, slices were reoxygenated in ACSF for $2 \mathrm{~h}$; OGD + compound group, in which slices were incubated with different $10 \mu \mathrm{M}$ target compounds (or 1 20 $\mu \mathrm{M}$ compound 5) for $30 \mathrm{~min}$ prior to and during OGD application; glutamate group, in which slices were subjected to $1 \mathrm{mM}$ glutamate in magnesiumfree artificial cerebrospinal fluid for $15 \mathrm{~min}$ (which had the following composition [in $\mathrm{mM}$ ]: $\mathrm{NaCl} 143$, $\mathrm{KCl} 5.4, \mathrm{CaCl}_{2}$ 1.8, $\mathrm{NaH}_{2} \mathrm{PO}_{4}$ 1.0, HEPES 2.4, glucose $5.6 \mathrm{pH}=7.4$ ). Slices were reoxygenated in ACSF for $2 \mathrm{~h}$; Glu +5 group, in which slices were incubated with 1-20 $\mu \mathrm{M} 5$ for 30 min prior to and during Glu application; $\mathrm{H}_{2} \mathrm{O}_{2}$ group, in which slices were subjected to $2 \mathrm{mM} \mathrm{H} \mathrm{H}_{2} \mathrm{O}_{2}$ for 30 min; $\mathrm{H}_{2} \mathrm{O}_{2}+5$ group, in which slices were incubated with different concentrations of $5(1-20 \mu \mathrm{M}) 30 \mathrm{~min}$ prior to and during $\mathrm{H}_{2} \mathrm{O}_{2}$ application.

After insult, slices were immersed into $2 \%$ TTC solution at $37{ }^{\circ} \mathrm{C}$ for $30 \mathrm{~min}$ and the wet weight was measured after rinsing twice with saline. A mixture of ethanol and dimethylsulfoxide (50:50) was added at a rate of $20 \mathrm{~mL}$ per $1 \mathrm{~g}$ of slices. After $24 \mathrm{~h}$ extraction in dark, the extracted liquid was added 
to $96-w e l l$ plates $(200 \mu \mathrm{L}$ per well), the absorbance $(A)$ at $490 \mathrm{~nm}$ of each well was measured by the ELISA reader (Elx $800^{\mathrm{uv}}$, Bio-TEK). The viability of brain slices was evaluated from the following equation: $\%$ tissue activities $=100 \% \times\left(A_{\text {injury }} / A_{\text {control }}\right)$.

\section{Conclusions}

In summary, we have synthesized a series of $N$-stearoylamino acids and their analogues by a facile route, and evaluated their activity against cerebral ischemia in vitro. Among these compounds, 4, 5 and 6 elicited higher activity in protecting rat brain slices against OGD insult. According to the preliminary SAR study, the neuroprotective activity of these lipoamino acids might be related with the fatty-acyl moieties of the tested compounds and the presence of a free carboxylic and hydroxyl groups on the branched chain of the amino acids. The evaluation of neuroprotective effects of $\mathbf{5}$ with three models implies that certain LAs could protect brain slices against OGD as well as $\mathrm{H}_{2} \mathrm{O}_{2}$ insult. Therefore, they might serve as candidate for the amelioration of cerebral ischemia and other cerebral insults.

\section{Acknowledgements}

This study was supported by National Natural Science Foundation of China (NO. 30873057), Key Basic Project of Shanghai Municipal Science and Technology Commission (No. JC1413600), Science and Technology Development Foundation from Shanghai Municipal Health Bureau (NO: 2007085). The authors express their appreciation to Li-Ping Shi of Shanghai Institute of Organic Chemistry for her help in ${ }^{1} \mathrm{HNMR}$ and ${ }^{13} \mathrm{CNMR}$ measuring.

\section{References and Notes}

1. Harukuni, I.; Bhardwaj, A. Mechanisms of brain injury after global cerebral ischemia. Neurol. Clin. 2006, 24, 1-21.

2. Ong, W.Y.; Farooqui, A.A. Iron, neuroinflammation, and Alzheimer's disease. J. Alzheimers Dis. 2005, 8, 183-200.

3. Mosley, R.L.; Benner, E.J.; Kadiu, I.; Thomas, M.; Boska, M.D.; Hasan, K.; Laurie, C.; Gendelman, H.E. Neuroinflammation, oxidative stress and the pathogenesis of Parkinson's disease. Clin. Neurosci. Res. 2006, 6, 261-281.

4. Pérez de la Ossa, N.; Dávalos, A. Neuroprotection in cerebral infarction: the opportunity of new studies. Cerebrovasc. Dis. 2007, 24, 153-156.

5. LinksPoewe, W. The need for neuroprotective therapies in Parkinson's disease: A clinical perspective. Neurology 2006, 66, 2-9.

6. Golde, T.E. The therapeutic importance of understanding mechanisms of neuronal cell death in neurodegenerative disease. Mol. Neurodegener. 2009, 4, 8-13

7. Zhou, M.; Xu, W.; Liao, G.H.; Bi, X.N.; Baudry, M. Neuroprotection against neonatal hypoxia/ischemia-induced cerebral cell death by prevention of calpain-mediated mGluRlalpha truncation. Exp. Neurol. 2009, 218, 75-82.

8. Abe, K. Neuroprotective therapy for ischemic stroke with free radical scavenger and gene-stem cell therapy. Rinsho Shinkeigaku 2008, 48, 896-898. 
9. Bye, N.; Habgood, M.D.; Callaway, J.K.; Malakooti, N.; Potter, A.; Kossmann, T.; MorgantiKossmann, M.C. Transient neuroprotection by minocycline following traumatic brain injury is associated with attenuated microglial activation but no changes in cell apoptosis or neutrophil infiltration. Exp. Neurol. 2007, 204, 220-233.

10. Ginsberg, M.D. Neuroprotection for ischemic stroke: Past, present and future. Neuropharmacology 2008, 55, 363-389.

11. Galve-Roperh, I.; Aguado, T.; Rueda, D.; Velasco, G.; Guzmán, M. Endocannabinoids: A new family of lipid mediators involved in the regulation of neural cell development. Curr. Pharm. Des. 2006, 12, 2319-2325.

12. Micale, V.; Mazzola, C.; Drago, F. Endocannabinoids and neurodegenerative diseases. Pharmacol. Res. 2007, 56, 382-392.

13. Bahr, B.A.; Karanian, D.A.; Makanji, S.S.; Makriyannis, A. Targeting the endocannabinoid system in treating brain disorders. Expert. Opin. Investig. Drugs 2006, 15, 351-365.

14. Burstein, S. The elmiric acids: Biologically active anandamide analogs. Neuropharmacology 2008, 55, 1259-1264.

15. Burstein, S.H.; Adams, J.K.; Bradshaw, H.B.; Fraioli, C.; Rossetti, R.G.; Salmonsen, R.A.; Shaw, J.W.; Walker, J.M.; Zipkin, R.E.; Zurier, R.B. Potential anti-inflammatory actions of the elmiric (lipoamino) acids. Bioorg. Med. Chem. 2007, 15, 3345-3355.

16. Huang, S.M.; Bisogno, T.; Petros, T.J.; Chang, S.Y.; Zavitsanos, P.A.; Zipkin, R.E.; Sivakumar, R.; Coop, A.; Maeda, D.Y.; De Petrocellis, L.; Burstein, S.; Di Marzo, V.; Walker, J.M. Identification of a new class of molecules, the arachidonyl amino acids, and characterization of one member that inhibits pain. J. Biol. Chem. 2001, 276, 42639-42644.

17. Wang, Z.J.; Li, G.M.; Nie, B.M.; Lu, Y.; Yin, M. Neuroprotective effect of the stearic acid against oxidative stress via phosphatidylinositol 3-kinase pathway. Chem. Biol. Interact. 2006, 160, $80-87$.

18. Blumberg, S.; Vallee, B.L. Superactivation of thermolysin by acylation with amino acid Nhydroxysuccinimide esters. Biochem. 1975, 14, 2410-2419.

19. Mckennon, M.J.; Meyers, A.I.; Drauz, K.; Schwarm M. A convenient reduction of amino acids and their derivatives. J. Org. Chem. 1993, 58, 3568-3571.

20. Bhaskar, J.V.; Periasamy, M. Selective reduction of carboxylic acids into alcohols using $\mathrm{NaBH}_{4}$ and $\mathrm{I}_{2}$. J. Org. Chem. 1991, 56, 5964-5965.

21. Xue, Q.S.; Yu, B.W.; Wang, Z.J.; Chen, H.Z. Effects of ketamine, midazolam, thiopental, and propofol on brain ischemia injury in rat cerebral cortical slices. Acta. Pharmacol. Sin. 2004, 25, $115-120$.

22. Lipton, P. Ischemic cell death in brain neurons. Physiol. Rev. 1999, 79, 1431-1568.

23. Mathew, K.S.; McLaughlin, D.P.; Ziabari, L.H.; Toner, C.C.; Street, P.C.; Hisgrove, E.; Bezzina, E.L.; Stamford, J.A. Rapid quantification of ischemic injury cerebroprotection in brain slices using densitometric assessment of 2,3,5-triphenyltetrazolium chloride staining. J. Neurosci. Methods 2000, 102, 43-51.

24. Tureyen, K.; Vemuganti, R.; Sailor, K.A.; Dempsey, R.J. Infarct volume quantification in mouse focal cerebral ischemia: A comparison of triphenyltetrazolium chloride and cresyl violet staining techniques. J. Neurosci. Methods 2004, 139, 203-207. 
25. Toner, C.C.; Miline, A.J.; Blatchford, K.L.; McLaughlin, D.P.; Stamford, J.A. An assessment of the cerebroprotective potential of volatile anaesthetics using two independent methods in an in vitro model of cerebral ischemia. Brain Res. 2002, 958, 390-398.

26. Bickler, P.E.; Hansen, B.M. Hypoxia-tolerant neonatal CA1 neurons: relationship of survival to evoked glutamate release and glutamate receptor-mediated calcium changes in hippocampal slices. Brain Res. Dev. Brain Res. 1998, 106, 57-69.

27. Zhang, Y.B.; Kan, M.Y.; Yang, Z.H.; Ding, W.L.; Yi, J.; Chen, H.Z.; Lu, Y. Neuroprotective effects of N-stearoyltyrosine on transient global cerebral ischemia in gerbils. Brain Res. 2009, 1287, 146-156.

28. Anderson, G.W.; Zimmerman, J.E.; Callahan, F.M. The use of esters of N-hydroxysuccinimide in peptide synthesis. J. Am. Chem. Soc. 1964, 86, 1839-1842.

Sample Availability: Samples of compounds 1-17 are available from the authors.

(C) 2009 by the authors; licensee Molecular Diversity Preservation International, Basel, Switzerland. This article is an open-access article distributed under the terms and conditions of the Creative Commons Attribution license (http://creativecommons.org/licenses/by/3.0/). 